\begin{tabular}{|l|l|}
\hline Postprint Version & 1.0 \\
\hline Journal website & $\underline{\text { http://content.healthaffairs.org/content/31/2/426 }}$ \\
\hline Pubmed link & $\underline{\text { http://www.ncbi.nlm.nih.gov/pubmed/22323174 }}$ \\
\hline DOI & $10.1377 /$ hlthaff.2011.0912 \\
\hline
\end{tabular}

This is a NIVEL certified Post Print, more info at http://www.nivel.eu

\title{
Early Results From Adoption Of Bundled Payment For Diabetes Care In The Netherlands Show Improvement In Care Coordination
}

DiNNY H. DE BAKKER ${ }^{1},{ }^{*}$, JEROEN N. STRUIJS $^{2}$, CAROLINE B. BAAN ${ }^{3}$, JOOP RAAMS ${ }^{4}$, JAN-ERIK DE WILDT ${ }^{5}$, HUBERTUS J.M. VRIJHOEF ${ }^{6}$ AND FREDERIK T. SCHUT ${ }^{7}$

${ }^{1}$ Dinny H. de Bakker(D.deBakker@nivel.nl) is a senior researcher at the Netherlands Institute for Health Services Research, in Utrecht.

${ }^{2}$ Jeroen N. Struijs is a senior researcher at the Netherlands National Institute for Public Health and the Environment, in Bilthoven.

${ }^{3}$ Caroline B. Baan is a senior researcher at the Netherlands National Institute for Public Health and the Environment.

${ }^{4}$ Joop Raams is a general practitioner at the Health Centre Kattenbroek, in Amersfoort, the Netherlands.

${ }^{5}$ Jan-Erik de Wildt is a business management director at De Ondernemende Huisarts, a primary care company, in Tilburg, the Netherlands.

${ }^{6}$ Hubertus J.M. Vrijhoef is a professor in the Department of Chronic Care at Tilburg University, in the Netherlands.

${ }^{7}$ Frederik T. Schut is a professor at the Institute of Health Policy and Management at Erasmus University Rotterdam, in the Netherlands.

\begin{abstract}
In 2010 a bundled payment system for diabetes care, chronic obstructive pulmonary disease care, and vascular risk management was introduced in the Netherlands. Health insurers now pay a single fee to a contracting entity, the care group, to cover all of the primary care needed by patients with these chronic conditions. The initial evaluation of the program indicated that it improved the organization and coordination of care and led to better collaboration among health care providers and better adherence to care protocols. Negative consequences included dominance of the care group by general practitioners, large price variations among care groups that were only partially explained by differences in the amount of care provided, and an administrative burden caused by outdated information and communication technology systems. It is too early to draw conclusions about the effects of the new payment system on the quality or the overall costs of care. However, the introduction of bundled payments might turn out to be a useful step in the direction of risk-adjusted integrated capitation payments for multidisciplinary provider groups offering primary and specialty care to a defined group of patients.
\end{abstract}

Many countries are seeking ways to better integrate the delivery of services and to provide more effective and less expensive care. For example, the US health care system has begun experimenting with bundled payments-paying a single fee for all medical services involved in an episode of care, such as a 
hospitalization —and accountable care organizations. ${ }^{1-4}$ In the Netherlands, numerous initiatives have been introduced since 2007 to improve the quality of care for chronically ill patients. ${ }^{5}$ The fragmentary funding of these initiatives hampered the establishment of long-term programs for the first three years. But in 2010 a bundled payment approach for diabetes care, chronic obstructive pulmonary disease care, and vascular risk management began to be implemented nationwide.

In this bundled payment model, health insurers pay a single fee to a principal contracting entity-a new legal entity called a care group-to cover all elements of primary care for patients with a specific chronic disease. Care groups consist of multiple health care providers and are often owned by general practitioners.

The Dutch government appointed a committee to evaluate the experience with the bundled payment system. This article discusses the main findings of the evaluation so far, as well as its implications for the applicability of bundled payment in general.

First, we describe the background and the basic premises of the bundled payment system, its goals, and the means used to reach them. Second, we describe the Dutch evaluation approach. Third, we report initial experiences with the system, based on our research findings and group interviews with stakeholders. Finally, we discuss the main policy questions raised by bundled payments in the Netherlands, compare the Dutch system with similar initiatives in the United States, and explore possible future directions for bundled payment.

\section{THE BACKGROUND OF THE DUTCH BUNDLED PAYMENT SYSTEM}

The context of the Dutch bundled payment system is described in the online Appendix. ${ }^{6}$ Two weaknesses in the Dutch health care system in general led to the introduction of this new system of payment for the chronically ill.

The first weakness is that primary care has been provided mainly in small physician practices that lack the capability to deliver a spectrum of needed care to the chronically ill. The average number of general practitioners per practice is $2.2 .^{7}$ Fifty-seven percent of these practices have no formal collaboration with practitioners of other primary care disciplines, such as physiotherapists or pharmacists. ${ }^{8}$ This makes it difficult to coordinate the care of patients with chronic diseases. A major cause of the fragmented organization of primary care is fragmented funding. Dutch general practitioners are paid according to a system that combines capitation and fee-for-service payments, whereas other primary care providers, such as physiotherapists, are paid on a fee-for-service basis.

The second weakness concerns the strict division between primary and specialty care. This division works well for acute problems, when the primary care filter limits patients' use of expensive specialists to necessary care. But for the chronically ill, who need both generalist and specialist care on an ongoing basis, the division obstructs the delivery of integrated care. Financing primary and specialist care separately hinders collaboration. This is because the efficiency gains from such a collaboration are rarely passed on to primary care providers and are likely to harm the financial interests of specialists.

Many initiatives have been introduced to increase the efficiency and improve the quality of diabetes care in the Netherlands. ${ }^{9}$ However, the fragmentary funding of these initiatives hampered the establishment of nationwide, sustainable programs. Legal barriers and differences in culture among medical disciplines also hindered the provision of integrated care, but the funding system seemed easier to change, and doing so had the potential to help lower other barriers.

\section{The Basic Premises Of Bundled Payment}

Several European countries have encountered similar problems in organizing disease management and have sought to improve their payment systems. ${ }^{10}$ The bundled payment system is the Dutch solution to the above-mentioned problems. It makes it possible for different elements of care for specific chronic diseases to be purchased, delivered, and billed as a single product or service.

Health insurers pay a single fee to a principal contracting entity — the care group-which serves as the general contractor and is responsible for organizing care and ensuring its delivery. The term care group refers to the principal contracting organization involved in a bundled payment contract with an insurer, not to the health care providers who actually deliver the care. The care group either delivers the various components of care itself or subcontracts with other health care providers, such as general practitioners, laboratories, dietitians, and specialists, to deliver them. The price for each bundle of services is negotiated 
between the insurer and the care group, and the fees for the subcontractors are negotiated with the care group.

The services to be included in generic care bundles have been described in disease-specific health care standards. ${ }^{11}$ These have been set at the national level in the Netherlands and agreed on by national associations of providers and patients. Promoting self-management and individual care plans for patients are innovative elements in the standards. Services in the care bundles are fully covered by the basic insurance that is mandatory for all Dutch citizens, which means that these services require no additional payment from patients. The standards specify only the treatment activities. In an attempt to encourage competition among providers, the standards do not specify the discipline of the provider who delivers the care.

Regulated competition among care groups for contracts with health insurers and among subcontractors for contracts with care groups are designed to provide appropriate incentives for well-coordinated care at a reasonable price. The contracts specify the obligations of the care group to provide the insurer with performance indicators for both processes (for example, the percentage of patients who had foot examinations in the previous twelve months) and outcomes (for example, the percentage of patients whose blood sugar levels are under control).

Currently, the new bundled payment system is voluntary. Insurers and providers are free to use it or stick to the traditional way of paying for health care. After the transition stage ends in 2012, the evaluation committee appointed by the minister of health will recommend whether or not the system should be maintained, changed, or expanded.

The evaluation committee consists of a multidisciplinary team of scientists with expertise in primary care, health economics, and integrated chronic care; a general practitioner who is on the board of a care group; and the manager of a care group. The committee's work is supported by researchers from the National Institute for Public Health and the Environment. The members of the committee and the researchers are the authors of this article, which is based on the first and second official interim reports of the committee submitted to the Dutch minister of health. The final report will be published later in 2012.

\section{STUdy DATA AND METHODS}

The evaluation committee developed a framework for assessing the bundled payment system. Research questions were derived from an analysis of the theory behind the system. The questions concern the main and side effects of the system's implementation and the conditions for that implementation. The analysis considered the perspective of patients, insurers, care groups, and subcontracted health care providers.

The material presented in this article is based on a secondary analysis of research, the perceptions of the members of the evaluation committee, and the results of four roundtable discussions with stakeholders from the different perspectives listed above. ${ }^{12}$

\section{NATIONWIDE IMPLEMENTATION OF BUNDLED PAYMENT}

In 2007 the Netherlands began experimenting with a bundled payment approach in ten care groups with a focus on diabetes. The experiments were evaluated by the National Institute for Public Health and the Environment. The results showed that the introduction of bundled payments and care groups had both positive and negative consequences, as well as some unknown effects. ${ }^{5,13}$

The positive consequences were better collaboration, better process quality (adherence to protocols), and more transparency. The negative consequences were dominance of the care groups by general practitioners, large price variations that were only partially explained by differences in the provision of care, and an administrative burden. That burden was a result of the fact that information and communication technology systems were not adapted to the new situation, which requires multidisciplinary registration and the provision of quality indicators. The effects of implementing bundled payment on patient outcomes such as blood sugar levels and costs were unknown.

In September 2009 the Dutch Parliament approved the nationwide implementation of bundled payment for diabetes care, chronic obstructive pulmonary disease care, and vascular risk management. The number of care groups increased sharply in anticipation of the new payment system. By March 2010 more than 100 
care groups had been established, and about 80 percent of all Dutch general practitioners were participating in a care group for diabetes care. ${ }^{14}$

The care groups were almost exclusively owned by general practitioners and operated on a regional scale. In all of the care groups, general practitioners and practice nurses - nurses who are mainly involved in performing checkups for the chronically ill—provided diabetes care. Subcontracted care was provided by dietitians (in 69 percent of the care groups); internists (65 percent), mostly involved on a consultative basis; ophthalmologists (58 percent); and laboratories (58 percent). ${ }^{14}$

It is still too early to draw conclusions about the effects of the bundled payment system on the quality or overall cost of care. However, the introduction of the system led to considerable debate among the different stakeholders. We describe the issues debated from the perspective of patient organizations, insurers, care groups, and subcontracted health care providers.

\section{Patient Organizations}

Patient organizations expressed the view that the traditional provision of primary care in the Netherlands is fragmented and consequently results in the absence of integrated care. Involved in the development of health care standards, these organizations typically stressed the importance of promoting patients' selfmanagement and the development of individual care plans.

The organizations argued that it is still too early to assess whether the new system of bundled payment contributes to more integrated and better coordinated care. In fact, they reported little experience-either positive or negative - with the system. Many patients might not be aware that they are included in a bundled payment program, because bills go directly to their insurer-which might explain the lack of experience reported by patients. Patient organizations did not report that selective subcontracting of primary care providers by care groups limited patients' choice of providers.

\section{Insurers}

Although health insurers generally endorsed the aim of better integrated care, they differed in their views of the bundled payment system. Most insurers supported the new system for diabetes and have signed contracts with most of the new care groups for the provision of diabetes care. However, insurers see the bundled payment as a kind of "black box," because they pay a fixed price per patient without being informed at the patient level about what consultations take place. Performance indicators are provided only at the aggregated level of the care group.

Normally, the price for each bundle of services is negotiated between the insurer and the care group and is paid in the form of a fixed price per patient with the relevant diagnosis. Subcontractors are paid on a feefor-service basis and negotiate their fees with the care group.

However, the largest insurer, Achmea, prefers to pay a separate fee to the general practitioner for the coordination of care in addition to the regular capitation fee that the general practitioner receives for each patient registered in his or her practice. Other providers in the program are paid not by the care group but directly by the insurer on the usual fee-for-service basis.

Achmea's primary concern about the bundled payment approach is that it is unclear which services the insurer is paying for. This concern is supported by research showing large variations among care groups with regard to price as well as to reported performance information., ${ }^{5,11}$ An analysis of a sample of eighty contracts showed that prices and requirements regarding transparency and quality were not related. ${ }^{15}$

Worries about "double funding" also play a role. It is difficult for insurers to check whether the treatment of diabetes patients with other chronic conditions is paid for twice, both via the bundled payment and via the traditional fee-for-service payment that general practitioners may charge for each consultation (in addition to the fixed fee for each patient registered in their practices). Furthermore, insurers reported fears that care groups will cherry-pick patients, selecting for the bundled payment system only those whose conditions are relatively stable and simple and leaving the more difficult and expensive cases to be paid for in the traditional way. At present, there is no empirical evidence of such behavior.

Another problem that insurers see in the new system is the extra administrative costs resulting from the contracts between insurers and care groups and between care groups and subcontractors. These are extra costs because the regular contracts between insurers and providers still exist for health problems and diseases that are not included in the bundled payment system.

Finally, insurers also expressed concerns about the lack of competition associated with the dominant market position of the new care groups. In many regions there is only one care group, usually owned by 
most of the local general practitioners. The analysis of contracts mentioned above showed that higher prices were paid in regions that had fewer care groups than in regions with more groups. ${ }^{15}$

\section{Care Groups}

Managers of care groups were generally positive about the organizational improvements in care under the bundled payment system. They reported improved collaboration within primary care and between primary care providers and specialists. Among the positive aspects mentioned was the ability of the care group to steer the care process, by enforcing adherence to protocols or by selecting good subcontractors. The managers also reported being increasingly able to supply health care providers with feedback about their performance relative to the average care group performance and to give insurers information about performance. However, the information technology in most care groups was not yet adequate to deliver all of the needed information.

Several care groups complained about insurers’ unwillingness to conclude bundled payment contracts. The groups pointed out that insurers could refuse to conclude contracts because of their powerful position in the highly concentrated insurance market. In 2010, 90 percent of the Dutch population had insurance from one of four major health insurers, while the remaining six small insurers had established a purchasing cooperative. ${ }^{16}$ Despite the high market concentration, price competition among insurers is strong, resulting in low profit margins (0.5 percent in 2010) ${ }^{17}$ So far, there is no evidence that insurers exploit their regional buying power to obtain unreasonably low prices from care groups.

Furthermore, care groups were worried about the abundant and time-consuming red tape created by the need to sign contracts with multiple insurers. The fact that insurers use different payment methods caused problems especially in regions where the largest insurer's practices were not followed by other insurers. In such cases, care groups had to deal with two quite different payment systems at the same time.

Several care groups also reported difficulties in assigning correct payments to subcontractors when more than one bundled payment was applicable to patients with other chronic conditions. For example, with diabetes patients at risk for vascular complications, the activities of a dietitian might fall under two types of bundled payment.

Furthermore, care groups reported that savings in specialist care resulting from good performance by the groups could not be fully passed along to primary care providers in the form of shared savings. This is because the reimbursement of hospitals and medical specialists is legally separated from payments to primary care providers.

\section{Subcontracted Providers}

Subcontractors concluded that the implementation of the bundled payment system improved the coordination of care. However, they worried about the possible exploitation or exclusion of individual care providers as a result of the powerful bargaining position of care groups. The subcontractors feared that traditional primary care partners such as dietitians, laboratories, and physiotherapists might be excluded because care groups could choose cheaper solutions. For example, the care groups could direct nurses employed by a primary care practice to give patients dietary advice, instead of subcontracting that type of care to better-qualified but more expensive dietitians.

So far, only anecdotal evidence exists for such behavior. For example, we have seen no solid evidence of the exploitation of subcontractors by undercutting their prices. Rather, subcontractors-especially providers of physical therapy-have organized themselves into regional groups to negotiate with care groups, thus strengthening the subcontractors' bargaining position.

Another concern reported by subcontractors is that general practitioners have a potential conflict of interest because they are simultaneously commissioning care-as owners of the care group-from subcontractors and providing care themselves. Care providers reported that the financial aspects of a contract tend to dominate the discussion, instead of the quality of care.

Subcontractors also reported positive effects of bundled payments. One example was that their record keeping improved as a result of the formalized working arrangements between care groups and individual providers.

General practitioners expressed the concern that disease-based financing, such as the bundled payment approach, will result in a compartmentalization of care, requiring patients to go to different general practitioners for different diseases. This outcome would be at odds with the idea that primary care should be comprehensive and patient-centered. Patients with diabetes visit their general practitioner less often because 
Bakker, D.H. de, Struijs, J.N., Baan, C.B., Raams, J., Wildt, J.E. de, Vrijhoef, H.J.M., Schut, F.T. Early results from adoption of bundled payment for diabetes care in The Netherlands show improvement in care coordination. Health Affairs: 2012, 31(2), 426-433

of their diabetes than for other reasons, ${ }^{18}$ which demonstrates the importance of a patient-centered rather than a disease-oriented approach.

\section{DISCUSSION}

The new system of bundled payment led to important changes in the financing and delivery of chronic care in the Dutch health care system. In a relatively short period of time, care groups were created throughout the country, providing integrated, multidisciplinary care for patients with diabetes and-to a lesser extent- those with chronic obstructive pulmonary disease and at risk for vascular problems.

In two respects, these arrangements constituted a major break with the past. First, they forced disciplines within primary care to collaborate routinely, whereas in the past such collaboration was more ad hoc and voluntary. Second, the introduction of regulated competition meant that negotiations with insurers on price and quality took place at the regional level, whereas in the past they had taken place at the national level among organizations of providers and insurers, working within regulatory constraints imposed by the government.

\section{Lessons For The United States}

The experiences of the Dutch bundled payment system are of particular interest to the United States, with the introduction of bundled payment initiatives and accountable care organizations in the Affordable Care Act of 2010. ${ }^{1,3,18}$ The Dutch and US initiatives are both aimed at improving the incentives for efficient, high-quality, well-coordinated, and patient-centered care.

Yet there are also important differences. Whereas the Dutch bundled payment system is targeted at specific chronic diseases and outpatient care, the US bundled payment initiative is targeted at inpatient and postacute care. In comparison to the Dutch care groups, accountable care organizations in the United States have a much broader scope, including hospital care.

Accountable care organizations also have to satisfy stringent and complex legal requirements, such as the required reporting of thirty-two quality measures. Although the final rule on accountable care organizations, released on October 20,2011, considerably reduced the requirements that were initially proposed, barriers to becoming an accountable care organization still seem quite substantial, and the financial viability of such organizations is unknown. ${ }^{19,20}$

In contrast, in the Netherlands there were only minor legal requirements for establishing care groups. Furthermore, no major investments were required because most providers continued to work in the prevailing small and medium-size practices. The tremendous growth in the number of care groups indicates that the negotiated payment levels - particularly those for diabetes care-made forming or joining such a group very attractive. The downside of the minimal requirements for care groups is that quality reporting is still in its infancy, and several care groups have obtained very large regional market shares.

Both the new care groups and insurers had no experience with negotiating about the organization and payment of integrated care. Care groups also had to learn how to manage their relationships with subcontractors. Subcontractors had to follow guidelines more closely than in the past and to keep records in a more structured way, often in a separate system alongside their own system. Given the novelty of these developments, it is not surprising that there is much variation in performance among care groups.

Just as there are US predecessors for accountable care organizations, several primary care organizations similar to the current Dutch care groups had been established well before the introduction of the bundled payment system. Some of these older care groups in particular show positive results in outcomes and in limiting the need for specialist care. ${ }^{5}$ Most of these groups had a lengthy tradition of collaboration and welldeveloped leadership.

At the other extreme, some newly established groups seem to be driven mostly by financial incentives. They see the new system chiefly as a different way to charge for care-including that provided to patients who have a preliminary stage of diabetes — and show no real improvement in the quality of care they provide.

It is up to insurers to determine whether they get value for money based on a complex set of structure and outcome indicators. Many of these indicators are not yet readily available for new programs such as bundled payment. Thus, it is often difficult for insurers to check whether they are charged for care more than once and whether the care has been delivered as agreed. Health care standards are broadly defined, which is appropriate because care has to be tailored to each patient's individual situation. But that lack of precision contributes to insurers' uncertainty about whether they are getting value for the money. 
Even more fundamental is the relatively powerful position of the care groups in a region. Despite the fact that the Dutch Healthcare Authority can counteract the abuse of market power-for example, by setting maximum prices-it is unclear whether this gives care groups sufficient incentives to provide high-quality care at a reasonable price. This uncertainty at least partially explains the reluctance of health insurers to support the new payment system.

\section{The Future Of Bundled Payment In The Netherlands}

In the future, success in paying for primary care through bundled payment depends on achieving higher quality at affordable cost. Even in well-performing care groups, it is likely to take years before cost savings become visible. Will policy makers be able to wait, given current heavy pressure to contain health care costs? The evaluation committee has initiated a study on the effects of bundled payments on the total costs of care, including the payments' effects on hospitalization. The first results of this study are expected in mid-2012.

Further implementation of bundled payments for other chronic diseases is being considered in the Netherlands. However, this would make the problem of how to deal with patients with multiple diseases even more complex. Eventually, the introduction of bundled payment might turn out to be a useful step in the direction of risk-adjusted integrated capitation payment for multidisciplinary provider groups offering primary and specialist care for a defined group of patients. Risk-adjusted payments should be based on the risk profile of the patient population. Policy makers or health insurers setting those payments could benefit from the experiences with the risk-equalization scheme for Dutch health insurers that has been developed during the past two decades. ${ }^{21}$

\section{ACKNOWLEDGMENTS}

The authors thank the staff of ZonMw, especially Annette Pietersen, for providing secretarial support to the evaluation committee on bundled payment.

\section{ABOUT THE AUTHORS: DINNY H. DE BAKKER, JEROEN N. STRUIJS, CAROLINE B. BAAN, JOOP RAAMS, JAN-ERIK DE WILDT, HUBERTUS J.M. VRIJHOEF \& FREDERIK T. SCHUT}

In this month's Health Affairs, Dinny de Bakker and coauthors report on a rapid transformation of primary care practice in the Netherlands. In 2010 a bundled payment system was introduced for diabetes and several other conditions; meanwhile, nearly all general practitioners have been organized into "care groups.” Early signs are that the changes have improved care coordination, but it's too early to assess the impact on the overall cost or quality of care.

De Bakker is a senior researcher at the Netherlands Institute for Health Services Research and a professor of structure and organization of primary care at Tilburg University, in the Netherlands. He chairs the national evaluation committee that is advising the Dutch minister of health on further implementation of bundled payments for chronic care in the Netherlands. His coauthors are members of the evaluation committee or the research team supporting the committee. De Bakker holds a doctorate in geography from Utrecht University.

Jeroen Struijs is a senior researcher at the National Institute for Public Health and the Environment in the Netherlands. He earned a doctorate in disease management from Amsterdam University.

Caroline Baan is also a senior researcher at the National Institute for Public Health and the Environment. She earned a doctorate in health services research from Erasmus University Rotterdam.

Joop Raams is a general practitioner at the Health Centre Kattenbroek, in Amersfoort, the Netherlands. He is the chair of a regional association of provider groups in the central part of the country. He holds a master's degree in general practice from the Free University of Amsterdam and a medical degree from the University of Groningen.

Jan-Erik de Wildt is a business management director at the primary care company De Ondernemende Huisarts. He also teaches a master class for board members and directors in primary care organizations at Tilburg University. He earned a master's degree in health administration from the Tias/Nimbas Business School at Tilburg University. 
Bakker, D.H. de, Struijs, J.N., Baan, C.B., Raams, J., Wildt, J.E. de, Vrijhoef, H.J.M., Schut, F.T. Early results from adoption of bundled payment for diabetes care in The Netherlands show improvement in care coordination. Health Affairs: 2012, 31(2), 426-433

Bert Vrijhoef is a professor of chronic care at Tilburg University and a senior scientist at the Netherlands Organization for Applied Scientific Research. He holds a master's degree in health policy and management from Erasmus University Rotterdam and a doctorate in medical sociology from Maastricht University.

Erik Schut is a professor of health economics and health policy and director of research at the Institute of Health Policy and Management, Erasmus University Rotterdam. He received a master’s degree in economics and a doctorate in health economics from Erasmus University.

\section{NOTES}

1. Berwick D, Gilfillan R. Accelerating innovation at the Centers for Medicare and Medicaid Services. Health Affairs Blog [blog on the Internet]. 2011 Oct 2 [cited 2011 Dec 12]. Available from: http://healthaffairs.org/blog/2011/10/21/accelerating-innovation-at-the-centers-for-medicare-andmedicaid-services/

2. Fisher ES, Shortell SM. Accountable care organizations. JAMA. 2010;304(15):1715-6.

3. Rosenthal MB, Cutler DM, Feder J. The ACO rules-striking the balance between participation and transformative potential. N Engl J Med. 2011;365(4):e6.

4. Cutler D. How health reform must bend the cost curve. Health Aff (Millwood). 2010;29(6):1131-5.

5. Struijs JN, van Til JT, Baan CA. Experimenting with a bundled payment system for diabetes care in the Netherlands: the first tangible effects [Internet]. Bilthoven, the Netherlands: National Institute for Public Health and the Environment; 2010 [cited 2012 Jan 10]. Available from: http://www.rivm.nl/bibliotheek/rapporten/260224002.pdf

6. Netherlands Institute for Health Services Research. Beroepsregistraties [Internet]. Utrecht: Netherlands Institute for Health Services Research; [cited 2011 Dec 18]. Available for download from: http://www.nivel.nl/beroepenindezorg

7. Hansen J, van Greuningen M, Batenburg RS . Monitor multidisciplinaire samenwerking binnen de eerste lijn. Utrecht: Netherlands Institute for Health Services Research; 2010.

8. Vrijhoef HJ, Spreeuwenberg C, Eijkelberg IM, Wolffenbuttel BH, van Merode GG. Adoption of disease management model for diabetes in region of Maastricht. BMJ. 2001;323(7319):983-5.

9. Gress S, Baan CA, Calnan M, Dedeu T, Groenewegen P, Howson H, et al.Co-ordination and management of chronic conditions in Europe: the role of primary care-position paper of the European Forum for Quality Care. Qual Prim Care. 2009;17(1):75-86.

10. Nederlandse Diabetes Federatie. NDF Zorgstandaard: transparantie en kwaliteit van diabeteszorg voor mensen met diabetes type 2. Amersfoort: NDF; 2007.

11. De Bakker D, Raams J, Schut FT, Vrijhoef HJM, de Wildt JE. Eerste rapportage van de evaluatiecommissie integrale bekostiging. The Hague: ZonMw; 2011.

12. Struijs JN, Baan CA. Integrating care through bundled payments-lessons from the Netherlands. N Engl J Med. 2011;364(11):990-1.

13. Van Til JT, de Wildt JE, Struijs JN. De organisatie van zorggroepen anno 2010. Huidige stand van zaken en de ontwikkelingen in de afgelopen jaren. Bilthoven: National Institute for Public Health and the Environment; 2011.

14. Van Dijk CE, Swinkels ICS, Lugt M, Korevaar JC. Integrale bekostiging: evaluatie van verwachte effecten op kwaliteit, toegankelijkheid, en betaalbaarheid. Utrecht: Netherlands Institute for Health Services Research; forthcoming.

15. Nederlandse Zorgautoriteit. Marktscan zorgverzekeringsmarkt. Utrecht: Nederlandse Zorgautoriteit; 2011.

16. Vektis. Zorgverzekeraars en zorgfinanciering. Zeist, the Netherlands: Vektis; 2011.

17. Van Dijk C, Rijken M, de Bakker D, Verheij R, Groenewegen P, Schellevis F. Anders is niet per se beter: kanttekeningen bij functionele bekostiging. Medisch Contact. 2009;64(22):973-6.

18. Berwick DM. Making good on ACOs' promise-the final rule for the Medicare Shared Savings Program. N Engl J Med. 2011;365(19):1753-6.

19. Casalino L, Shortell S. The ACO race is on: navigating the terrain. Health Affairs Blog [blog on the Internet]. 2011 Oct 24 [cited 2011 Dec 12]. Available from:

http://healthaffairs.org/blog/2011/10/24/the-aco-race-is-on-navigating-the-terrain/

20. Van de Ven WPMM, Schut FT. Universal mandatory health insurance in the Netherlands: a model for the United States? Health Aff (Millwood). 2008;27(3):771-81. 